\title{
"Double Prosthesis Implantation": Biometry and Refractive Outcomes in Combined Intraocular Lens and Artificial Iris Surgery
}

This article was published in the following Dove Press journal: Clinical Ophthalmology

\author{
Christian Mayer \\ Ramin Khoramnia (D) \\ Department of Ophthalmology, \\ University Hospital Heidelberg, \\ University of Heidelberg, Heidelberg, \\ Germany
}

Purpose: To assess the biometry and postoperative refraction in iris repair using ArtificialIris in combination with an intraocular lens (IOL).

Setting: Department of Ophthalmology, University Hospital Heidelberg, University of Heidelberg, Germany.

Design: Retrospective observational study.

Methods: We included 44 aniridic and aphakic eyes for IOL implantation in combination with iris prosthesis reconstruction. The iris prostheses were either sutured into the ciliary sulcus and fixed by transscleral suturing or were implanted together with a capsular tension ring and the IOL in the capsular bag. The primary outcomes measured were pre- and postoperative best corrected visual acuity (CDVA), objective and subjective refraction, anterior chamber depth and optical biometry comparing common IOL formulae.

Results: Reasons for surgery were trauma (39 eyes), iatrogenic causes ( 1 eye), aniridic state after severe iritis ( 2 eyes) or iris tumor ( 2 eyes). Monocular CDVA improved significantly $(\mathrm{p}<0.0001)$ from median $0.55 \log \mathrm{MAR}(0.0$ to 1.98$)$ to $0.16 \log \mathrm{MAR}(-0.08$ to 2.0$)$. There were no significant differences between the postoperative target refraction calculated by the formulae "Haigis", "Hoffer-Q", "SRK/T" and "Holladay 1" ( $p=0.68)$. The absolute deviation from target refraction did not differ significantly between the formulae $(p=0.87)$. Median target refraction was $-0.42 \mathrm{D}(-4.0$ to 1.68$)$. Postoperatively median spherical equivalent was $0.00 \mathrm{D}$ ( -5.38 to 2.38 ). Median absolute deviation from target refraction after 5 months of follow-up was $0.98 \mathrm{D}$ (0.06 to 5.17).

Conclusion: Postoperative refraction using common techniques and using preoperative biometry revealed a well predictable postoperative refraction. There is no correction factor needed.

Keywords: aniridia, aphakia, artificial iris, secondary IOL implantation

\section{Introduction}

Acquired iris and lens injuries usually lead to a high level of suffering in patients, both due to a pronounced sensitivity to glare and the lack of refractive correction. The extent of the iris defect ranges from persistent traumatic mydriasis and partial iris losses to complete aniridia. In addition, there is often preexisting cataract or aphakia without preservation of the lens capsule or zonular fibres as part of the preexisting disease. ${ }^{1}$ Treatment options with printed iris contact lenses and light protection glasses should be tried first. Secondly, surgical interventions using various total or partial implantable iris prostheses, also in combination with intraocular lenses (IOLs), would be an option ${ }^{2,3}$ (Figure 1). The complex clinical picture requires a very detailed explanation of the procedure to the
Correspondence: Christian Maye University Hospital Heidelberg, University of Heidelberg, Im Neuenheimer Feld, 400, Heidelberg, 69120, Germany Email christian.mayer@med.uni-heidelberg. de 
patient with careful planning of the iris and IOL reconstruction. ${ }^{4}$ Particularly, it is difficult to predict the effective lens position ${ }^{5}$ in procedures involving a combined implantation of the iris prosthesis and IOL. These cases are rather difficult to examine and depict a challenge when it comes to the selection of the correct IOL power using optical biometry. Moreover, difficulties in taking the measurements due to corneal scars, astigmatism and retinal impairments are to be considered. Since 2011, the first author has implanted over 120 artificial irides made of silicone in a wide variety of initial situations. ${ }^{6-8}$ This work will evaluate the use of biometry data and the refractive outcome in patients, who had undergone combined implantation of an artificial iris and IOL.

\section{Methods}

This retrospective observational case series comprised 59 eyes of 56 patients who were treated with a combined implantation of an artificial IOL and an artificial iris implant at a University Hospital in southern Germany over a period of seven years (2011-2018). Complete follow-up data were available in 44 eyes.

The presented data are based on an individually manufactured silicone iris prosthesis (ArtificialIris ${ }^{\circledR}$, HumanOptics, Erlangen, Germany). The device received the CE marking in 2011 and is the only iris prosthesis that received FDA approval (2018) for the treatment of vision and cosmetic problems arising from congenital, surgical or traumatic aniridia in adults
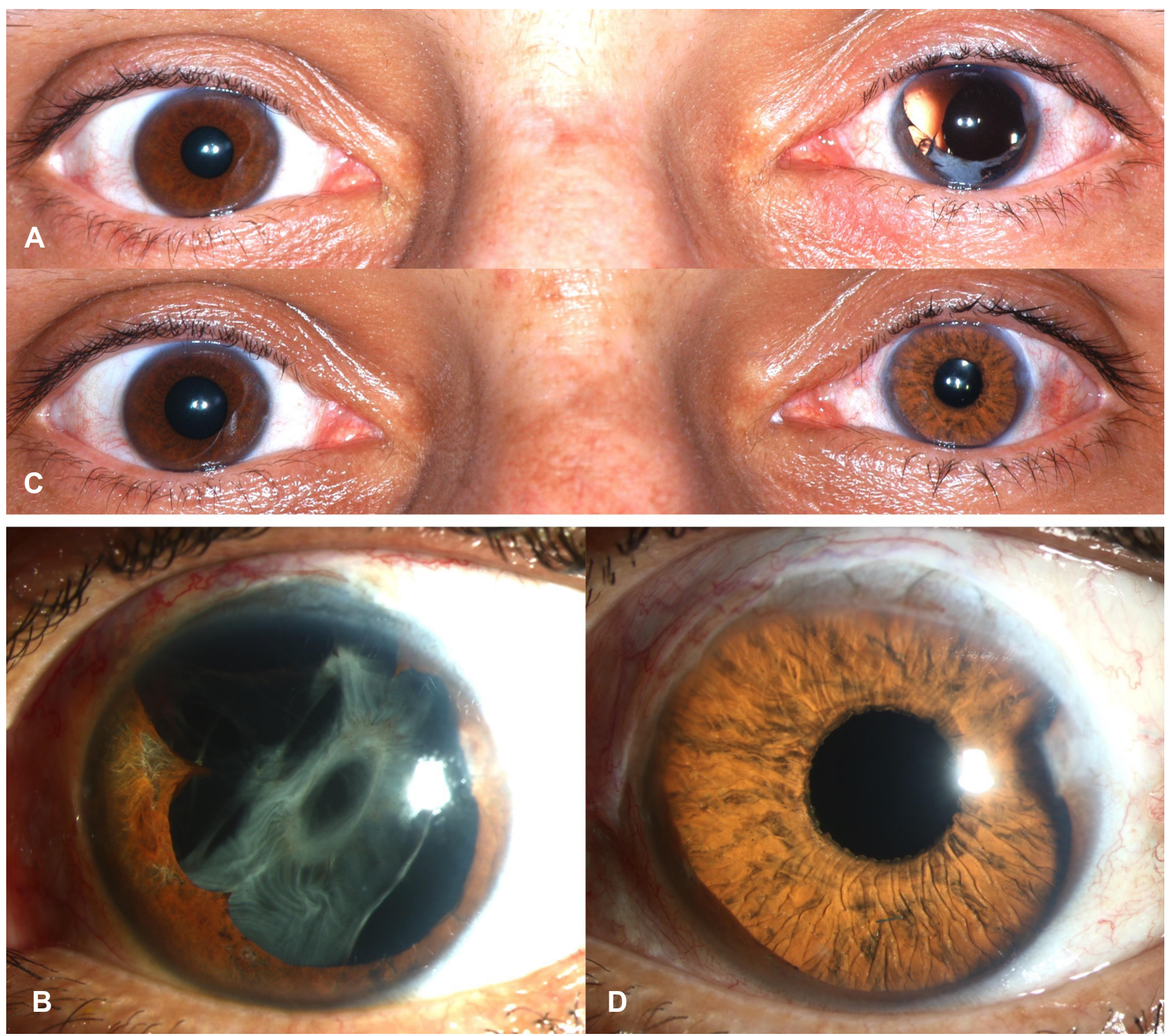

Figure I Pre- $(\mathbf{A}$ and $\mathbf{B})$ and postoperative $(\mathbf{C}$ and $\mathbf{D})$ findings in a patient with traumatic partial aniridia and pseudophakia. The patient suffered from visual disturbances including glare due to partial aniridia, decentered IOL and capsular phimosis. 
and children. The study was conducted according to the tenets of the Declaration of Helsinki, and approval by the Institutional Review Board (Ethics Committee Munich) was obtained. Details of the surgical procedure were explained to all patients. Informed consent was obtained from all participants for the procedure and their medical records to be accessed for this study. Optical Biometry was performed with the Zeiss IOL Master 500 (Zeiss, Oberkochen, Germany) using the biometry formulae "Haigis", "Hoffer-Q", "SRK/T" and "Holladay 1". Postoperative target refraction was taken from the formulae in the order just mentioned.

Patients received either a one-piece hydrophilic acrylic IOL ( $n=35)$ (ASPIRA-aAY, HumanOptics AG, Erlangen, Germany) or a distinct PMMA IOL $(n=9)$ (Type 81B, Morcher GmbH, Stuttgart, Germany) in combination with the artificial iris implant.

We described several different techniques for simultaneous implantation of an artificial intraocular lens and artificial iris prosthesis elsewhere in detail. ${ }^{6,9}$ For this patient cohort, we used four of these techniques which we summarize here:

Technique $1(n=15)$ : In patients with iris defects and cataract, the artificial iris prosthesis can be implanted together with any sort of injectable IOL and a capsular tension ring in the capsular bag ("in the bag"). There is a need for a slightly larger capsulorhexis $(>6.0 \mathrm{~mm})$ in comparison with a standard cataract surgery. The combined thickness of the three implants (approximately $2.0 \mathrm{~mm}$ ) is somewhat less than the thickness of a normal human lens (approximately 5.0 to $6.0 \mathrm{~mm}$ ) so that there is no "shortage of space". The correct trepanation size is crucial for a good postoperative centration of the new pupil on the optical axis. However, determining the adequate iris diameter is even more difficult with the capsular bag-fixed variant (approximately $9.5 \mathrm{~mm}$ ) than with the sulcus fixation (approximately 11.5 to $12.5 \mathrm{~mm}$ ) of the artificial iris. In addition, during the implantation into the capsular bag, stress on the zonular fibers should not be underestimated. Two implants in the capsular bag increase the difficulty to predict the effective lens position. We chose the tunnel width to not exceed $2.8 \mathrm{~mm}$.

Technique $2(n=6)$ : In 6 patients with cataract and iris defect the IOL was implanted in the capsular bag in the same way as for normal cataract surgery procedures. Afterwards the iris prosthesis was implanted using an injector system in the ciliary sulcus. The tunnel width did not exceed $2.8 \mathrm{~mm}$.

Technique $3(n=10)$ : In the case of a missing lens capsule, a stable position of the IOL and iris prosthesis in the sulcus ciliaris requires a scleral fixation with sutures. In this two-step technique, the PMMA IOL is sutured to the sclera first.
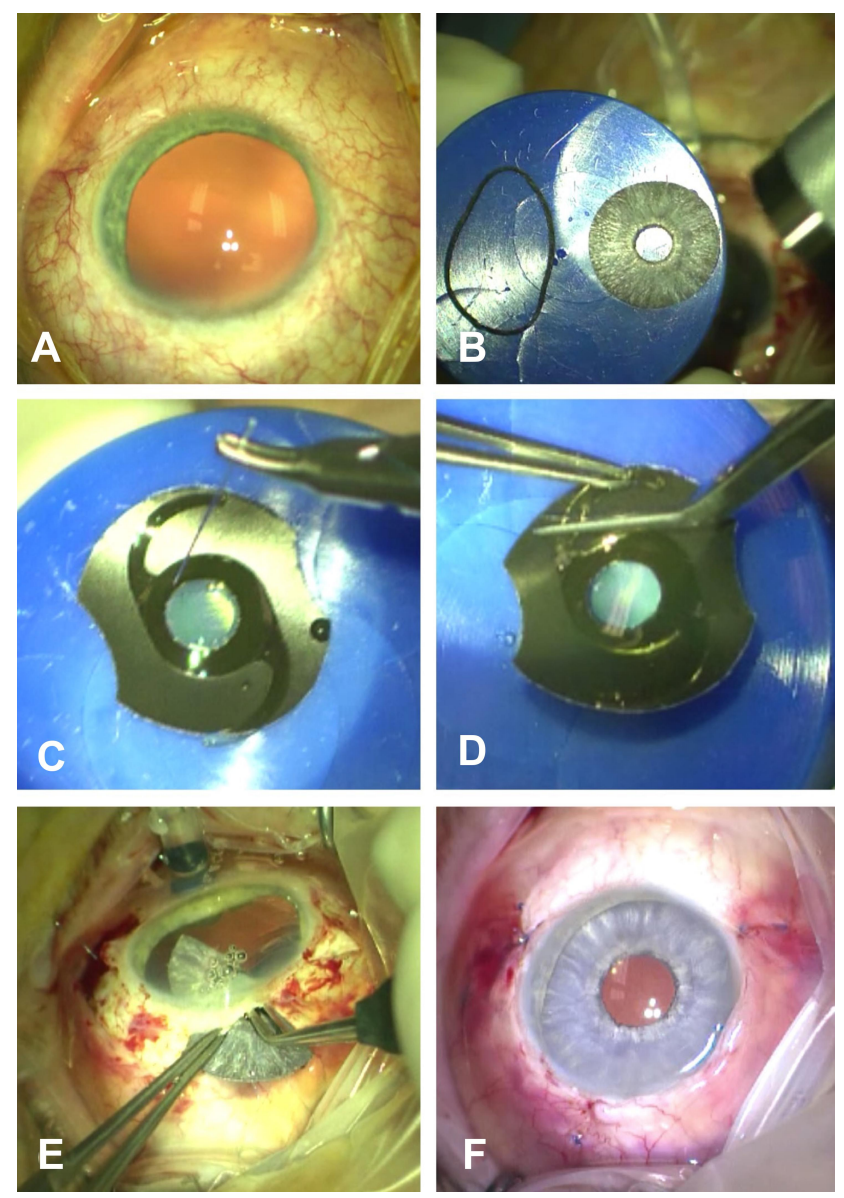

Figure 2 Implantation of an artificial iris in combination with an IOL: (A) Preoperative finding. (B) Trephination of the artificial iris and (C) suturing of the IOL onto the backside of the artificial iris. (D) Removal of the not required haptics. (E) Implantation of the folded combined implant through a $7 \mathrm{~mm}$ corneal-scleral incision in the ciliary sulcus. Fixation with non-resorbable 9-0 sutures in the 3 and 9 o'clock position. (F) Finding at the end of surgery.

Secondarily, the iris prosthesis is also fixed to the sclera using durable 10.0 polypropylene threads. It seems useful to fix the lens haptics to the sclera at 3 and 9 o'clock and the iris sutures at the 6 and 12 o'clock position to avoid axial tilting and to achieve good and stable centering. In such cases, it is extremely difficult to predict the effective lens position of the scleral fixated IOL. Furthermore, it is unclear whether the additional iris prosthesis might have an impact on the effective lens position.

Technique $4(\mathrm{n}=13)$ : Alternatively, any commercially available artificial lens can be sewn onto the back of the silicone iris like a "sandwich", then folded and implanted in the eye (Figure 2). We used a mono-piece hydrophilic IOL in order to keep the sandwich implant as compact as possible. The haptics of the IOL that are not required can be removed. Suture fixation is prepared extraocular usually at the 3 and 9 o'clock position of the artificial iris. Correspondingly, when the 
Table I Demographic and Preoperative Data of the Patients

\begin{tabular}{|c|c|c|}
\hline & Median (Min-Max) & Mean $\pm S D$ \\
\hline Eyes/Patients & \multicolumn{2}{|c|}{$44 / 41$} \\
\hline Gender $(f / m)$ & \multicolumn{2}{|c|}{$12 / 29$} \\
\hline Age at surgery (years) & $57.0(28.0$ to 84.0$)$ & $55.9 \pm 15.3$ \\
\hline Time diagnosis to surgery (months) & 36.0 (1.0 to 792$)$ & $164.7 \pm 217.4$ \\
\hline CDVA (logMAR) & $0.55(0.00$ to 1.98$)$ & $0.65 \pm 0.48$ \\
\hline Sphere (D) & $1.50(-7.25$ to 16.50$)$ & $3.63 \pm 6.08$ \\
\hline Cylinder (D) & $-1.50(-7.75$ to -0.25$)$ & $-1.73 \pm 1.44$ \\
\hline SE (D) & 0.31 ( -7.88 to 16.25$)$ & $2.98 \pm 6.26$ \\
\hline IOL power (D) & 21.25 (II.0 to 31.0$)$ & $21.20 \pm 3.49$ \\
\hline $\mathrm{ACD}(\mathrm{mm})$ & $3.53(2.29$ to 5.196$)$ & $3.63 \pm 1.03$ \\
\hline $\mathrm{AL}(\mathrm{mm})$ & 23.38 (21.26 to 28.39$)$ & $23.74 \pm 1.29$ \\
\hline Target refraction (D) & $-0.42(-4.0$ to 1.68$)$ & $-0.57 \pm 0.86$ \\
\hline
\end{tabular}

Abbreviations: CDVA, corrected distance visual acuity; SE, spherical equivalent; ACD, anterior chamber depth; AL, axial length.

sandwich is implanted, sutures are fixated at the 3 and 9 o'clock scleral positions as well. As a result, in this greatest possible individual reconstruction of an iris-lens diaphragm it is again difficult to predict the effective lens position.

Study parameters assessed preoperatively and at the five months follow-up were the following: manifest refraction; corrected distance visual acuity (CDVA); Postoperatively, the effective lens position was evaluated with the Pentacam (Oculus, Wetzlar, Germany).

We used Analyse-it ${ }^{\circledR}$ for Microsoft ${ }^{\circledR}$ Excel 5.11 for all statistical analyses. Decimal visual acuities and contrast sensitivity scores were converted into logMAR and logarithmic units, respectively. Hence, adjusted meter visions, such as counting fingers (CF), hand motion (HM), and light perception (LP) were defined as 1.9 (CF), 2.0 (HM) and 2.1 (LP) $\log$ MAR. The non-parametric Wilcoxon test for paired samples was used to compare CDVA. KruskalWallis test was used for comparison between the IOL power calculation formulae. All tests were two-tailed, and significance level was set at a p-value of 0.05 .

\section{Results}

In this retrospective observational study, we included 44 eyes of 41 patients. Demographic data are 29 male $(70.73 \%)$ and 12 female patients $(29.27 \%)$ with an average age of 57.0 years (28.0 to 84.0 years) (see also Table 1).
Reasons for iridic defects in combination with the need for IOL implantation were ocular trauma in 39 eyes $(88.64 \%)$, aniridia or persistent mydriasis following severe iritis in 2 eyes $(4.55 \%)$, tumor of the iris in 2 eyes $(4.55 \%)$ and iatrogenic aniridia in one eye $(2.27 \%)$. From these patients, 26 suffered from aphakia and 18 from cataract with need for surgery.

The mean implanted IOL Power was 21.2 D ( \pm 3.49$)$. At 5 months, monocular visual acuity could be measured for 44 eyes. It significantly improved compared to the preoperative values $(\mathrm{p}<0.0001) .64 \%(28 / 44)$ of patients had an improvement of $0.2 \log$ MAR or greater, $34 \%$ (15/ 44) had an improvement of less than $0.2 \log$ MAR or no change and $2 \%(1 / 44)$ lost $0.2 \log$ MAR or more. CDVA was better than or equal to $20 / 100$ for $100 \%$ of eyes and better than or equal to $20 / 25$ for $45 \%$ of eyes. IOP $(\mathrm{p}=0.409)$ and refractive astigmatism $(\mathrm{p}=0.975)$ did not change significantly. Table 2 shows the preoperative and postoperative values for those parameters.

There were no significant differences between the target refraction calculated by the formulae "Haigis", "Hoffer-Q", "SRK/T" and "Holladay 1" $(p=0.68)$. The absolute deviation from target refraction (Figure 3) did not differ significantly between the formulae $(p=0.87)$. Median target refraction was $-0.42 \mathrm{D}(-4.0$ to 1.68$)$. Postoperatively median spherical equivalent was 0.00 
Table 2 CDVA and Refraction Values

\begin{tabular}{|c|c|c|c|}
\hline & Preoperatively & Postoperatively & p-value \\
\hline \multicolumn{4}{|l|}{ CDVA (logMAR) } \\
\hline Median (range) & 0.55 (0.0 to 1.98$)$ & $0.16(-0.08$ to 0.70$)$ & $<0.0001$ \\
\hline Mean \pm SD & $0.65 \pm 0.48$ & $0.23 \pm 0.23$ & \\
\hline \multicolumn{4}{|l|}{ Sphere (D) } \\
\hline Median (range) & I.50 $(-7.25$ to 14.0$)$ & $0.50(-3.75$ to 4.25$)$ & 0.065 \\
\hline Mean \pm SD & $3.33 \pm 5.81$ & $0.51 \pm 1.61$ & \\
\hline \multicolumn{4}{|l|}{ Cylinder (D) } \\
\hline Median (range) & $-1.63(-7.75$ to -0.25$)$ & $-1.38(-6.75$ to 0.00$)$ & 0.975 \\
\hline Mean \pm SD & $-1.77 \pm 1.45$ & $-1.77 \pm 1.42$ & \\
\hline \multicolumn{4}{|c|}{ Spherical equivalent (D) } \\
\hline Median (range) & $0.25(-7.88$ to 14.0$)$ & $0.0(-5.38$ to 2.38$)$ & 0.064 \\
\hline Mean \pm SD & $2.67 \pm 5.98$ & $-0.34 \pm 1.72$ & \\
\hline
\end{tabular}

Abbreviation: CDVA, corrected distance visual acuity.

D (-5.38 to 2.38). Median absolute deviation from target refraction after 5 months of follow-up was $0.98 \mathrm{D}(0.06$ to 5.17). Tables 3 and 4 show the percentages of eyes within a certain range of deviation for each of the formulae. There were no significant differences $(p=0.28)$ in terms of absolute deviation from target refraction between the lens and implantation techniques (ie, ASPIRA-aAY attached or not attached to the iris implant or Type 81B IOL).

\section{Discussion}

Implantation of the ArtificialIris, and more specifically in combination with an intraocular lens, offers great functional and aesthetic outcomes ${ }^{10}$ in patients with iris and lens defects. With all feasible techniques, the correct

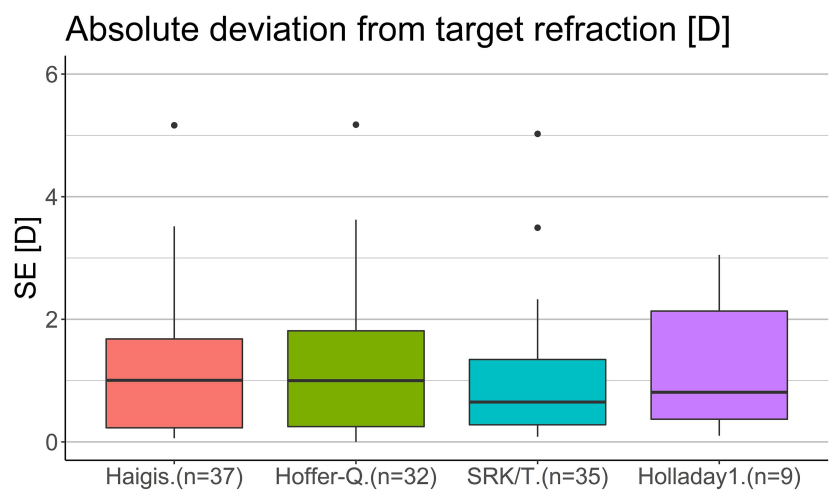

Figure 3 Comparison of the differences from target refraction [D] calculated with four common IOL power formulae and the achieved spherical equivalent (SE) [D]. trepanation size is crucial for a good postoperative centration of the new pupil, which in turn is important for a good aesthetic result. The target diameter of the iris prosthesis varies from technique (position in the sulcus) to technique (position in the capsular bag) and inter-individually.

The evaluation of the data shows a relatively flat learning curve, even for an experienced anterior and posterior section surgeon, with a minimum of 12 interventions until the complication rate had decreased significantly. Even for a surgeon with "pole-to-pole" experience the use of the iris implant is a challenge: The procedure is extraordinary and includes a special and variable range of intra- and postoperative complications. ${ }^{7,11}$ Therefore, surgeons should be well experienced and trained in such unique cases to avoid high complication rates and dissatisfaction with the outcomes. Overall, however, the iris silicone implant offers a good opportunity to help patients with extensive iris defects. $^{12}$ In a recent paper, a two-step approach in patients requiring both, silicone oil endotamponade and reconstruction of the iris, has been described. ${ }^{13}$ This approach proved to be a viable option. The outcomes were highly satisfying. Moreover, in most cases the implant leads to great functional outcomes. In the previous research, we found no differences in optical quality between different lens powers attached to the artificial iris. $^{14}$ In this clinical study, there were no differences between the two lens types in terms of postoperative refractive outcome and its deviation from target refraction. Therefore, functional outcomes do not appear to vary with 
Table 3 Number (n), Percentages and Cumulative Percentages of Deviation from Target Refraction to Postoperative SE for the Aspira-aAY IOL

\begin{tabular}{|c|c|c|c|c|c|c|c|c|c|c|c|c|}
\hline & \multicolumn{3}{|c|}{ Haigis $n=3$ I } & \multicolumn{3}{|c|}{ Hoffer-Q n=30 } & \multicolumn{3}{|c|}{ SRK/T $n=33$} & \multicolumn{3}{|c|}{ Holladay-I n=8 } \\
\hline & $\mathbf{n}$ & $\%$ & Cum. \% & $\mathbf{n}$ & $\%$ & Cum. \% & $\mathbf{n}$ & $\%$ & Cum. \% & $\mathbf{n}$ & $\%$ & Cum. \% \\
\hline $\pm 0.00 \mathrm{D}$ & 0 & 0 & 0 & I & 3 & 3 & 0 & 0 & 0 & 0 & 0 & 0 \\
\hline $\pm 0.50 \mathrm{D}$ & 11 & 35 & 35 & 9 & 30 & 33 & 12 & 36 & 36 & 3 & 38 & 38 \\
\hline $\pm 1.00 \mathrm{D}$ & 4 & 13 & 48 & 5 & 17 & 50 & 10 & 30 & 67 & 2 & 25 & 63 \\
\hline $\pm 1.50 \mathrm{D}$ & 6 & 19 & 68 & 6 & 20 & 70 & 4 & 12 & 79 & I & 13 & 75 \\
\hline $\pm 2.00 \mathrm{D}$ & 5 & 16 & 84 & 3 & 10 & 80 & 3 & 9 & 88 & 0 & 0 & 75 \\
\hline $\pm 2.50 \mathrm{D}$ & 2 & 6 & 90 & 4 & 13 & 93 & 2 & 6 & 94 & 2 & 25 & 100 \\
\hline $\pm 3.00 \mathrm{D}$ & 1 & 3 & 94 & 0 & 0 & 93 & 0 & 0 & 94 & 0 & 0 & 100 \\
\hline $\pm 3.50 \mathrm{D}$ & 0 & 0 & 94 & 0 & 0 & 93 & 1 & 3 & 97 & 0 & 0 & 100 \\
\hline $\pm 4.00 \mathrm{D}$ & I & 3 & 97 & I & 3 & 97 & 0 & 0 & 97 & 0 & 0 & 100 \\
\hline $\pm 4.50 \mathrm{D}$ & 0 & 0 & 97 & 0 & 0 & 97 & 0 & 0 & 97 & 0 & 0 & 100 \\
\hline $\pm 5.00 \mathrm{D}$ & 0 & 0 & 97 & 0 & 0 & 97 & 0 & 0 & 97 & 0 & 0 & 100 \\
\hline $\pm 5.50 \mathrm{D}$ & 1 & 3 & 100 & I & 3 & 100 & 1 & 3 & 100 & 0 & 0 & 100 \\
\hline
\end{tabular}

Table 4 Number (n), Percentages and Cumulative Percentages of Deviation from Target Refraction to Postoperative SE for the Type 8 IB IOL

\begin{tabular}{|c|c|c|c|c|c|c|c|c|c|c|c|c|}
\hline & \multicolumn{3}{|c|}{ Haigis $n=6$} & \multicolumn{3}{|c|}{ Hoffer-Q n=2 } & \multicolumn{3}{|c|}{$S R K / T n=2$} & \multicolumn{3}{|c|}{ Holladay-I $n=I$} \\
\hline & $\mathbf{n}$ & $\%$ & Cum. \% & $\mathbf{n}$ & $\%$ & Cum. \% & $\mathbf{n}$ & $\%$ & Cum. \% & $\mathbf{n}$ & $\%$ & Cum. \% \\
\hline $\pm 0.00 \mathrm{D}$ & 0 & 0 & 0 & 0 & 0 & 0 & 0 & 0 & 0 & 0 & 0 & 0 \\
\hline $\pm 0.50 \mathrm{D}$ & 3 & 50 & 50 & I & 50 & 50 & I & 50 & 50 & 0 & 0 & 0 \\
\hline $\pm 1.00 \mathrm{D}$ & 0 & 0 & 50 & 0 & 0 & 50 & 0 & 0 & 50 & 0 & 0 & 0 \\
\hline $\pm 1.50 \mathrm{D}$ & 2 & 33 & 83 & 0 & 0 & 50 & 0 & 0 & 50 & 0 & 0 & 0 \\
\hline $\pm 2.00 \mathrm{D}$ & I & 17 & 100 & 0 & 0 & 50 & I & 50 & 100 & 0 & 0 & 0 \\
\hline $\pm 2.50 \mathrm{D}$ & 0 & 0 & 100 & I & 50 & 100 & 0 & 0 & 100 & 0 & 0 & 0 \\
\hline $\pm 3.00 \mathrm{D}$ & 0 & 0 & 100 & 0 & 0 & 100 & 0 & 0 & 100 & 0 & 0 & 0 \\
\hline $\pm 3.50 \mathrm{D}$ & 0 & 0 & 100 & 0 & 0 & 100 & 0 & 0 & 100 & 1 & 100 & 100 \\
\hline $\pm 4.00 \mathrm{D}$ & 0 & 0 & 100 & 0 & 0 & 100 & 0 & 0 & 100 & 0 & 0 & 100 \\
\hline $\pm 4.50 \mathrm{D}$ & 0 & 0 & 100 & 0 & 0 & 100 & 0 & 0 & 100 & 0 & 0 & 100 \\
\hline $\pm 5.00 \mathrm{D}$ & 0 & 0 & 100 & 0 & 0 & 100 & 0 & 0 & 100 & 0 & 0 & 100 \\
\hline $\pm 5.50 \mathrm{D}$ & 0 & 0 & 100 & 0 & 0 & 100 & 0 & 0 & 100 & 0 & 0 & 100 \\
\hline
\end{tabular}

the two different lens types or whether they are attached to the iris implant or not. Results are also aesthetically satisfying $^{15}$ as the iris looks astoundingly like a natural iris. In any case, the possibility of a single-stage combined iris and lens surgery should be considered where possible and reasonable. Nonetheless, the extraordinary procedure of "double prosthesis implantation" should not be underestimated - regardless of the technique. 
As already reported in detail, ${ }^{16-18}$ haptic fixation of a foldable IOL on the back of the Artificiallris provides advantages regarding sutureless and knotless transscleral fixation. Although remaining foldable, the scleral-fixated IOL-iris complex cannot be inserted using an injector.

The combined implantation of an artificial lens and artificial iris can achieve good refractive results using standard biometry parameters. Postoperative refraction using common techniques and preoperative biometry revealed a well predictable postoperative refraction. There is no correction factor needed. However, deviation from the target refraction can occur in these oftentimes severely traumatized eyes. Corneal irregularities/scarring, for example, can lead to a decrease in the accuracy of optical biometry. Tilted IOLs have not been observed. The ArtificialIris generally offers the possibility to simultaneously correct aphakia when required, which substantially enables improvement of vision. ${ }^{19}$

\section{Data Sharing Statement}

The data used to support the findings of this study are available from the corresponding author upon request.

\section{Disclosure}

Dr Christian Mayer reports publication fee from HumanOptics. The authors report no other conflicts of interest in this work.

\section{References}

1. Viestenz A, Kuchle M. [Retrospective analysis of 417 cases of contusion and rupture of the globe with frequent avoidable causes of trauma: the Erlangen Ocular Contusion-Registry (EOCR) 1985 1995]. Klin Monbl Augenheilkd. 2001;218(10):662-669. doi:10.1055/ s-2001-18388. German.

2. Neuhann IM, Neuhann TF. Cataract surgery and aniridia. Curr Opin Ophthalmol. 2010;21(1):60-64. doi:10.1097/ICU.0b013e328333ea49

3. Frisina R, De Biasi CS, Londei D, Gambato C, Midena E. A new intraocular lens with artificial iris for treating a case of iris extrusion secondary to traumatic opening of a radial keratotomy. Eur J Ophthalmol. 2020;1120672120902035.

4. Wolff J. [Prosthetic iris devices]. Der Ophthalmologe. 2011;108 (8):714-719. doi:10.1007/s00347-011-2368-z. German.

Clinical Ophthalmology

\section{Publish your work in this journal}

Clinical Ophthalmology is an international, peer-reviewed journal covering all subspecialties within ophthalmology. Key topics include: Optometry; Visual science; Pharmacology and drug therapy in eye diseases; Basic Sciences; Primary and Secondary eye care; Patient Safety and Quality of Care Improvements. This journal is indexed on PubMed

Submit your manuscript here: https://www.dovepress.com/clinical-ophthalmology-journal
5. Norrby S. Sources of error in intraocular lens power calculation. $J$ Cataract Refract Surg. 2008;34(3):368-376.

6. Mayer C, Tandogan T, Hoffmann AE, Khoramnia R. Artificial iris implantation in various iris defects and lens conditions. $J$ Cataract Refract Surg. 2017;43(6):724-731.

7. Mayer CS, Laubichler AE, Khoramnia R, et al. Challenges and complication management in novel artificial iris implantation. J Ophthalmol. 2018;2018:3262068.

8. Mayer CS, Baur ID, Storr J, Khoramnia R. Complete anterior segment reconstruction: corneal transplantation and implantation of an iris prosthesis and IOL in a single surgery. Eur J Ophthalmol. 2021. doi:10.1177/1120672121991052

9. Mayer CS, Hoffmann AE. [Surgical treatment with an artificial iris]. Ophthalmologe. 2015;112(10):865-868. German.

10. Mayer CS, Hoffmann AM, Prahs P, Reznicek L, Khoramnia R. Functional outcomes after combined iris and intraocular lens implantation in various iris and lens defects. BMC Ophthalmol. 2020;20 (1):370. doi:10.1186/s12886-020-01621-8

11. Mayer CS, Laubichler AE, Masyk M, Prahs P, Zapp D, Khoramnia R. Residual iris retraction syndrome after artificial iris implantation. $\mathrm{Am}$ J Ophthalmol. 2019;199:159-166. doi:10.1016/j.ajo.2018.09.001

12. Mayer CS, Reznicek L, Hoffmann AE. Pupillary reconstruction and outcome after artificial iris implantation. Ophthalmology. 2016.

13. Mayer CS, Baur I, Storr J, Markard A, Khoramnia R. Surgical management for silicone oil barrier of traumatic aniridia with aphakia: suturing of temporary iris-diaphragm prior to final iris-lensdiaphragm implantation. Clin Ophthalmol. 2020;14:4439. doi:10.2147/OPTH.S284159

14. Mayer C, Son HS, Łabuz G, Yildirim TM, Auffarth GU, Khoramnia R. In vitro optical quality assessment of a monofocal IOL sutured to an artificial iris. J Cataract Refract Surg. 2020;46 (8):1184-1188. doi:10.1097/j.jcrs.0000000000000287

15. Yildirim TM, Khoramnia R, Masyk M, Son H-S, Auffarth GU, Mayer CS. Aesthetics of iris reconstruction with a custom-made artificial iris prosthesis. PLoS One. 2020;15(8):e237616. doi:10.1371/journal.pone. 0237616

16. Spitzer MS, Yoeruek E, Leitritz MA, Szurman P, Bartz-Schmidt KU. A new technique for treating posttraumatic aniridia with aphakia: first results of haptic fixation of a foldable intraocular lens on a foldable and custom-tailored iris prosthesis. Arch Ophthalmol. 2012;130 (6):771-775. doi:10.1001/archophthalmol.2011.1778

17. Gooi P, Teichman JC, Ahmed IIK. Sutureless intrascleral fixation of a custom-tailored iris prosthesis with an intraocular lens. $J$ Cataract Refract Surg. 2014;40(11):1759-1763. doi:10.1016/j.jcrs.20 14.09.015

18. Forlini C, Forlini M, Rejdak R, et al. Simultaneous correction of post-traumatic aphakia and aniridia with the use of artificial iris and IOL implantation. Graefes Arch Clin Exp Ophthalmol. 2013;251 (3):667-675. doi:10.1007/s00417-012-2254-7

19. Koch KR, Heindl LM, Cursiefen C, Koch H-R. Artificial iris devices: benefits, limitations, and management of complications. $J$ Cataract Refract Surg. 2014;40(3):376-382. doi:10.1016/j.jcrs.2013.08.051
Central and CAS, and is the official journal of The Society of Clinical Ophthalmology (SCO). The manuscript management system is completely online and includes a very quick and fair peer-review system, which is all easy to use. Visit http://www.dovepress.com/ testimonials.php to read real quotes from published authors. 